\title{
Analysis of patients diagnosed with primary cutaneous melanoma in the last six years in Hospital Erasto Gaertner: epidemiologic profile*
}

\author{
Tariane Friedrich Foiato ${ }^{1}$ \\ Marcos Flávio Montenegro ${ }^{2}$ \\ Larissa Beatriz Volski ${ }^{4}$
}

\author{
Bruno Rafael Kunz Bereza ${ }^{1}$ \\ Marina Riedi Guilherme ${ }^{3}$ \\ Juliano Camargo Rebolho
}

DOI: http:/ / dx.doi.org/10.1590/abd1806-4841.20185788

\begin{abstract}
BACKGROUND: Melanoma is one of the conditions with greater increase in incidence worldwide in recent decades. It is a skin cancer with potential high lethality and predominates in Caucasian adults. Treatment of primary cutaneous melanoma is essentially surgical and search for sentinel lymph node can modify the aggressiveness of the treatment.

Овлестіvе: To analyze the epidemiological profile of patients diagnosed with primary cutaneous melanoma, histopathological features and compare with literature data.

Methods: This is a retrospective, observational, single-center, case series study of patients with primary cutaneous melanoma, who underwent surgery between January 2008 and December 2013. The parameters include: Age, sex, clinical stage, date of surgery, tumor location, histological subtype, condition of surgical margins, Breslow thickness, mitotic index, presence of ulceration and metastasis on admission.

RESUlts: We included 321 melanoma patients who were treated at Hospital Erasto Gaertner. The population consisted of 58.9\% females and $41.1 \%$ males with an average age of $52.8 \pm 16.3$ years. As for the clinical stage, $51.1 \%$ were in the initial stage, $24.3 \%$ in the clinical stage II (A, B and C), 21.2\% in clinical stage III and 3.4\% with distant metastases. The most frequent location of the primary melanoma was the trunk, and the histological subtype was superficial spreading pattern. Intermediate and thick melanomas were the most frequent.

STUDY LIMITATIONS: This is a retrospective study and some information and data could be incomplete or absent.

CONCLUSION: The diagnosis and treatment of melanoma in early stages provides less morbidity and improved survival of patients. Understanding the biological behavior of tumor and knowing the local epidemiology guide health strategies.
\end{abstract}

Keywords: Diagnosis; Melanoma; Skin neoplasms

\section{INTRODUCTION}

Melanoma originates from the malignant transformation of melanocytes and is more predominant in Caucasian adults. This type of cancer can occur in any part of the body or any organ, however, cutaneous involvement is much more common $(91.2 \%) .{ }^{1} \mathrm{Cu}$ taneous melanoma represents $4 \%$ of tumors on the skin, has a high mortality, however, its incidence is low (2,960 new cases in men and 2,930 in women). The highest estimated rates in Brazil in men and women are seen in the South region. Its incidence has increased considerably over the last decades. In Brazil, the estimation of new cases was of 5,670 in $2016 .^{2}$

The high level of clinical suspicion to detect the condition in its early stages restricted the increase in the mortality of this condition (around 85\% in stages I and II). ${ }^{3,4}$

Treatment of primary cutaneous melanoma is essentially surgical, where the margins are defined radially between $1 \mathrm{~cm}-4 \mathrm{~cm}$, according to the thickness of the lesion. ${ }^{5,6}$ If surgical treatment of the

\footnotetext{
Received 17 March 2016.

Accepted 05 April 2017.

Work conducted at Hospital Erasto Gaertner, Curitiba (PR), Brazil.

Financial support: None.

Conflict of interest: None.

Department of Oncologic Surgery, Centro de Oncologia de Cascavel (CEONC), Cascavel (PR), Brazil.

Service of Skin and Melanoma, Hospital Erasto Gaertner, Curitiba (PR), Brazil.

Medical School Student, Universidade Federal do Paraná (UFPR), Curitiba (PR), Brazil.

Medical School Student, Faculdade Evangélica do Paraná (Fepar), Curitiba (PR), Brazil.
} 
primary lesion is not possible, other treatment modalities have been studied such as radiotherapy.

Sentinel lymph node was introduced by Morton et al. in 1992, and since 1998 it has been utilized in melanoma staging. Currently, it is recommended for lesions thicker than $0.76 \mathrm{~mm}$, with a mitotic index above 1 and/or ulcerated lesions of $1 \mathrm{~mm}$ or larger and clinical examination with no evidence of lymph node enlargement. ${ }^{8-10}$

Understanding the biological behavior of the tumor and knowing the local epidemiology guide health strategies. Early diagnosis by a high index of clinical suspicion changes the outcome and the expenses with public health.

The objective of this study is to analyze the profile of patients with the diagnosis of primary cutaneous melanoma seen at the Service of Skin and Melanoma at Hospital Erasto Gaertner, the characteristics of the tumor and to compare them with data in the literature.

\section{METHODS}

This is a retrospective, observational, single center case series study based on the collection of data from patients' files with primary cutaneous melanoma who underwent surgical treatment between January 2008 and December 2013. The series of cases is comprised of the experience of the Service of Skin and Melanoma at Hospital Erasto Gaertner. Initially, 383 patients were analyzed based on a diagnostic search; 62 patients were excluded because they did not meet all inclusion criteria, with 321 patients left for the analysis in the study (Figure 1).

The patients included in the study had a histopathological diagnosis of cutaneous melanoma and were seen at Hospital Erasto Gaertner, where they underwent surgical treatment in the period between January 2008 and December 2013. Patients with the diagnosis of primary cutaneous melanoma who were surgically treated in other institution, and patients with ocular or mucosal melanoma were excluded, as well as those with insufficient information available for the analysis of the main variables in their files.

The main parameters include: age, sex, clinical stage, date of the surgery, tumor location, histological subtype, surgical margins, Breslow thickness and mitotic index. The objective of the study is to correlate the parameters found in simple patients with the current literature, define the epidemiological profile and compare the sample with data from the Brazilian population.

In our service, patients referred from primary care either with a diagnosis by a biopsy performed elsewhere or by a suspicious lesion are included in a flowchart for melanoma treatment.

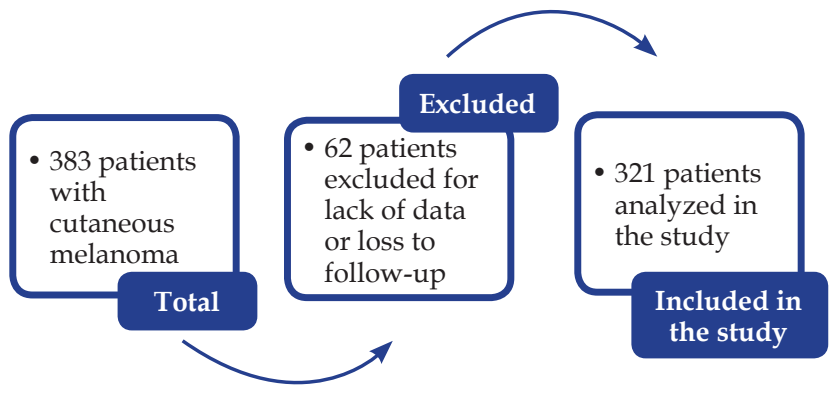

Figure 1: Patients included in the study
All lesions suspicious for melanoma are submitted to excisional biopsy with a 1-2mm margin. Incisional biopsy of pigmented lesions is considered in exceptional circumstances. Pathological diagnosis with the biopsy guides definitive treatment. After the diagnosis of invasive melanoma, patients are staged with abdominal ultrasound (US), chest $x$-ray, alkaline phosphatase (ALP) and lactate dehydrogenase $(\mathrm{LDH})$. For patients with an increased risk of metastasis, staging is performed with tomography. Further exams are performed individually depending on clinical abnormalities. For patients with no metastatic disease, primary cutaneous melanoma with a thickness of $<0.75 \mathrm{~mm}$, the treatment consists in a wider excision with surgical margins of at least $1 \mathrm{~cm}$. Since it is a retrospective study, at the time of the study, for melanomas with a thickness of $0.75 \mathrm{~mm}$ or more, a sentinel lymph node biopsy (SLNB) was performed and the wider excision had surgical margins of at least $2 \mathrm{~cm}$. Wider excision of surgical margins is standardized and the resection has a trapezoid configuration, in a way that the subcutaneous tissue is removed with wider safety margins. The deep level is limited to the deep fascia, included. Closure is performed with primary advancement, flap or skin graft.

For SLNB, patients undergo lymphoscintigraphy the day prior to the surgery. Patients are operated on in the morning with the technique of patent blue marking. The sentinel lymph node is prepared with hematoxylin \& eosin (H.E.). For patients with macroscopic involvement of the sentinel lymph node, resection of the lymph node chain if indicated. In cases of sentinel lymph node without macroscopic involvement, a immunohistochemical panel is performed to evaluate micro metastasis which, if present, is an indication for routine lymph node removal.

The decision regarding adjuvant treatment is made according to the criteria of the National Comprehensive Cancer Network (NCCN). Isolated metastasis that can be treated surgically are individually evaluated and the resection of the lesions is as recommended by the literature.

In our institution, the follow-up of melanoma patients is performed with periodical clinical consultations and follow-up exams such as: abdominal US, chest x-ray, ALP and LDH for the earlier stages. Further exams are requested according to the clinical symptoms of the patients. The staging system used was from the American Joint Committee on Cancer (AJCC), $7^{\text {th }}$ edition, 2010.

The research project was assessed and approved by the committee of ethics in research (CEP) of the Hospital Erasto Gaertner, number CAAE 32157214.5.0000.0098.

Informed consent was not needed because the analysis of the data was purely retrospective.

The statistical analysis was performed using IBM SPSS Statistics v.20. Categorical variables were described by frequency and percentage. For the age, mean \pm standard deviation was shown. LDH and ALP were described by median and quartiles. For the comparison of the clinical stages regarding LDH and ALP, the nonparametric test of Kruskal-Wallis was used. The association between metastasis on admission and the mitotic index was evaluated using the chi-square test. The values of $p<0.05$ indicated statistical significance. 


\section{RESULTS}

In total, 383 patients were analyzed and from those, 62 patients did not meet the inclusion criteria and were removed from the sample. In the final study, 321 patients were included, who had cutaneous melanoma and were treated in the period between January 2008 and December 2013.

TABLE 1: Percentage and numerical distribution of the patients according to the clinical stage (AJCC) and Breslow thickness. $\mathrm{NR}=$ not included in the pathology report

\begin{tabular}{lll} 
Variable & $\mathbf{n}$ & $\%$ \\
\hline Clinical stage & 37 & 11.5 \\
0 & 76 & 23.7 \\
IA & 51 & 15.9 \\
IB & 27 & 8.4 \\
IIA & 28 & 8.7 \\
IIB & 23 & 7.2 \\
IIC & 12 & 3.7 \\
IIIA & 24 & 7.5 \\
IIIB & 32 & 10.0 \\
IIIC & 11 & 3.4 \\
IV & & \\
Breslow thickness $(\mathbf{m m})$ & 103 & 32.1 \\
$\leq 1.0$ & 63 & 19.6 \\
$1.01-2.00$ & 44 & 13.7 \\
$2.01-4.00$ & 71 & 22.1 \\
$>4.00$ & 33 & 10.3 \\
In situ & 7 & 2.2 \\
NR* & & \\
\hline
\end{tabular}

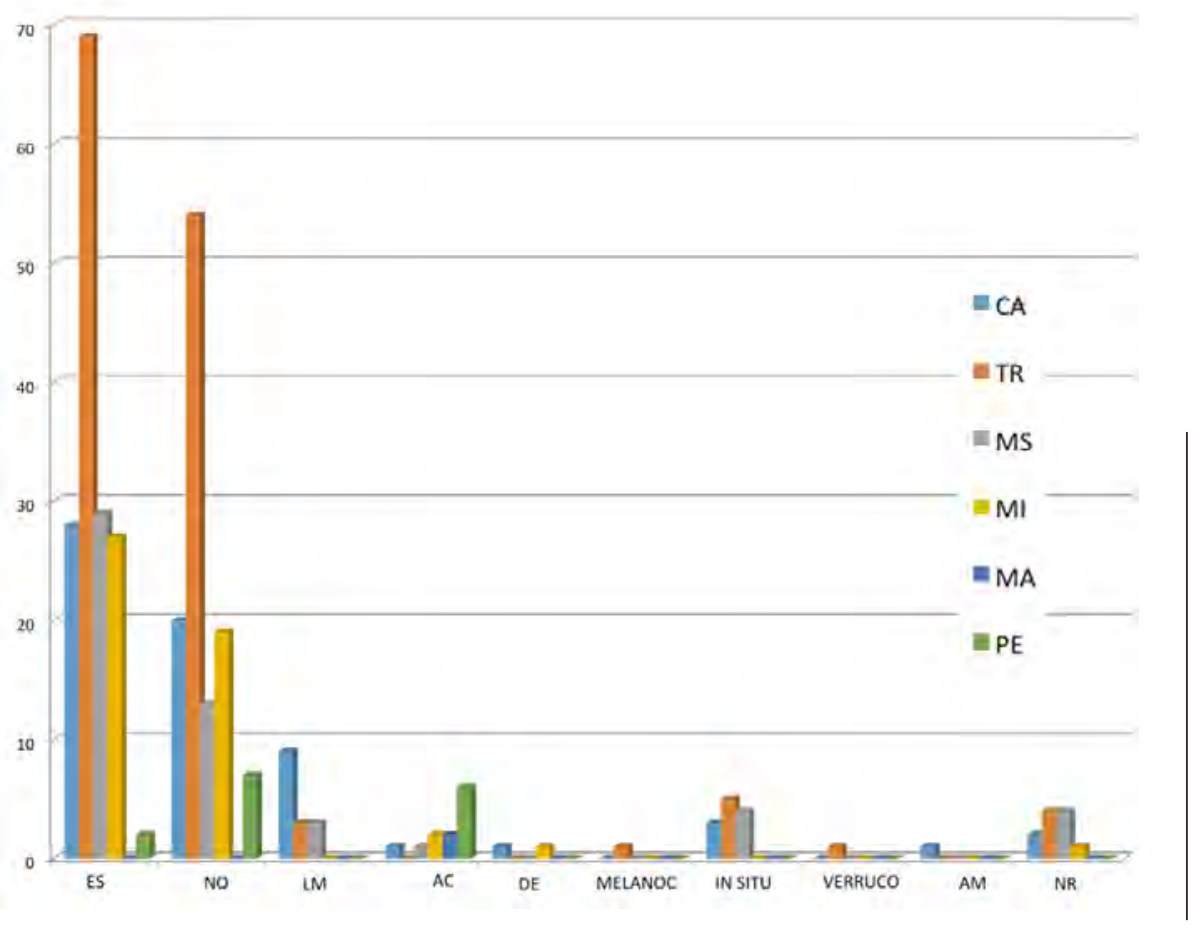

In regards to the gender of the patients, $58.9 \%$ were female and $41.1 \%$ were male. The mean age was $52.8 \pm 16.3$ years (ranging from 10 to 89 years with a median of 52 years). The distribution of the initial clinical stages and the thickness of the cutaneous melanoma (Breslow) are shown in table 1.

The most frequent site of the primary melanoma was the trunk (42.4\%), followed by the head (20.1\%), upper and lower limbs (16.7\% and $15.5 \%)$, foot and hand (4.6\% and $0.6 \%)$.

The analysis of the histopathological subtype of the patients showed that most patients head the superficial spreading melanoma subtype $(48 \%)$. The other histological types were as follows: nodular (35\%), lentigo maligna (4.6\%), acral (3.7\%), in situ $(3.7 \%)$ and desmoplastic $(0.6 \%)$. Other histological types found were: melanocarcinoma, verrucous melanoma, and amelanotic melanoma. The distribution of the frequency of the histological types and their anatomical site are illustrated in graph 1 . The application of a statistical test to infer about the association between the histological type and the anatomical site was not possible because the number of cases in some combinations of the two variables is very small. The presence of ulceration was observed in $32.7 \%$ of the cases. Satellitosis was found in only $8.1 \%$ of melanomas.

At the time of diagnosis, the median of LDH was 461 with interquartile amplitude of 397 to 532 (mean of. A539.7), LDH data available in 218 patients. Median for ALP was 74 with interquartile amplitude of 61 to 92 (mean of 83.7), data available in 204 patients. When comparing clinical stages to LDH, a significant difference $(p$ $=0.009$ ) was found, with the clinical stage IV significantly different from the others $(p<0.005$ in the comparisons of clinical stages two by two I, II and III exhibited the same behavior). No statistical difference was found between clinical stages in relation to $\operatorname{ALP}(p=0.266)$.

\section{Graph 1:}

Representation of the frequency of the histological type by anatomical sites. Histological types: $\mathrm{SS}=$ superficial spreading; $\mathrm{NO}=$ nodular; $\mathrm{LM}=$ lentigo maligna; $\mathrm{AC}=$ acral; $\mathrm{DE}=$ desmoplastic; MELANOC = melanocarcinoma; IN SITU = in situ; VERRUCO = verrucous; $\mathrm{AM}=$ amelanotic; $\mathrm{NR}=$ not reported . Anatomical sites: $\mathrm{HN}=$ head and neck; $\mathrm{TR}=$ trunk; $\mathrm{UL}=$ upper limb; $\mathrm{LL}=$ lower limb; $\mathrm{HA}=$ hand; $\mathrm{FO}=$ foot 


\begin{tabular}{|c|c|c|}
\hline CS & LDH & ALP \\
\hline 0 & $456(395-512)$ & $69(61-78)$ \\
\hline I & $463(393-541)$ & $72(61-93)$ \\
\hline II & $451(392-517)$ & $72(60-92)$ \\
\hline III & $461(406-532)$ & $75(61-88)$ \\
\hline IV & $666(523-843)$ & $92(71-94)$ \\
\hline
\end{tabular}

The distribution by clinical stage is found in table 2 .

SLNB was necessary in 201 patients $(62.6 \%)$. Removal of the main drainage lymph node chain was performed in 83 patients (25.9\%). The presence of lymph node micrometastasis was of $7 \%$. All surgical margins of the wider excisions were free of the tumor.

The presence of metastasis on admission was seen in 11 patients $(3.4 \%)$, the affected sites were: lungs, liver, central nervous system, adrenal, spleen, pancreas, retroperitoneum and bones. Enlarged lymph nodes on the initial clinical examination was seen in 30 patients.

Regarding the mitotic index evaluated in the samples, in $39.2 \%$, there was no mitoses. The presence of one mitosis was found in 46 cases (148\%), more than one to six mitoses in 75 cases $(24.1 \%)$, more than six mitoses in 68 cases $(21.9 \%)$. No significant association between the mitotic index and the presence of metastasis was found $(p=0.965)($ Table 3$)$.

\section{DISCUSSION}

Understanding the profile of the patient affected by melanoma is extremely important for the early diagnosis, as the prognosis worsens considerably for patients in more advanced stages. Because it is initially asymptomatic, early diagnosis is extremely difficult, with detection rates by the patients around $50 \%$ of cases. ${ }^{11,12}$ In our study, there was a higher proportion of women diagnosed with melanoma (58.6\% women vs $41.7 \%$ men), with a ratio of 1.4 woman for each man with melanoma, a feature that is distinct from what is found in the literature, where the ratio is around $1 \mathrm{M}: 1 \mathrm{~F}$, with a tendency of an increase in cases in males. ${ }^{2,12}$ In the USA, according to data from the National Cancer Institute, the incidence in the years 2008-2012 was of 28.2 cases/100,000 people in men to 16.8 cases/100,000 people in women.

During the period from 2008 to 2013, the age of the affected patients in the study was homogeneous, with a mean of 52.8 years (10-89 years) and around $40 \%$ between 50 and 69 years. Men had a more advanced age at diagnosis than women (means of $55.7 \pm 14.9$ and $50.8 \pm 17.0$ years, respectively).

Early diagnosis changes the natural history of the disease, patients in early stages (IA and IB) have a 10-year survival of around $90 \%{ }^{4}$ In our study, $39.6 \%$ of the patients were in this group. In clinical stages II (A, B and C), $24.3 \%$ of the patients were included and in stage III, there were $21.2 \%$ of the patients studied. The patients with the diagnosis of advanced disease, with distant metastasis,

\begin{tabular}{|c|c|c|c|c|}
\hline \multirow[t]{2}{*}{ Mitotic index } & \multicolumn{2}{|c|}{ No metastasis } & \multicolumn{2}{|c|}{ With metastasis } \\
\hline & $\mathrm{n}$ & $\%$ & $\mathbf{n}$ & $\%$ \\
\hline 0 & 119 & $39.1 \%$ & 3 & $42.9 \%$ \\
\hline 1 & 45 & $14.8 \%$ & 1 & $14.3 \%$ \\
\hline 2 to 6 & 73 & $24.0 \%$ & 2 & $28.6 \%$ \\
\hline$>6$ & 67 & $22.0 \%$ & 1 & $14.3 \%$ \\
\hline
\end{tabular}

comprised 3.4\%. A survey of the histopathological reports from 1999 to 2004 in the state of Santa Catarina demonstrated approximately $30 \%$ of patients with melanoma had stages I and II. ${ }^{13}$ In contrast, in the United Kingdom, data from the Cancer Research UK showed that around $80 \%$ of the patients at the time of diagnosis were in those same stages.

The histological subtype most commonly found was superficial spreading, with $48 \%$, followed by the nodular and lentigo maligna types (38\% and 6\%), also found by many authors. ${ }^{14-16}$ The nodular subtype characterizes by an initial vertical growth, thicker Breslow and consequently a higher risk for regional and distant involvement. Thick tumors were predominantly nodular $(77 \%$, $55 / 71$ ). The lentigo maligna subtype was seen in patients with more advance age. Our sample size is quite relevant, of the surveys performed in the state of Paraná till now, it has the larger number of cases. It reveals a rate of intermediate and thick melanomas, a total of $55.4 \%$, and thin of $42.4 \%$. in the city of Londrina-PR, it was also found that around $70 \%$ of the tumors had a Clark III and IV level of invasion. ${ }^{17}$ In nationwide studies from the South and Northeast regions, a higher percentage of thin tumors was seen, ranging from 62 to $73 \% \cdot^{13,18}$

The values of LDH and ALP at the time of diagnosis were elevated only in stage IV.

Women were proportionately more affected with primary lesions on the lower limbs and men on the trunk, what is compatible with the areas exposed to solar radiation. Data already shown by other authors. ${ }^{14,15,19}$ There was no difference regarding tumor thickness between the sexes.

SLNB was necessary in 201 patients $(62.6 \%)$, and when positive, removal of the affected lymph node chain was indicated. There is evidence that this management increases overall survival. ${ }^{20,21}$

Lymph node enlargement on the initial clinical examination was seen in 30 patients $(9.3 \%)$, sent to FNA or to removal of lymph nodes according to the tumor characteristics. The correlation between thick tumors and the presence of enlarged lymph nodes on physical examination was directly related, $80 \%$ of those had Breslow $>2 \mathrm{~mm}$.

Distant metastasis on admission was found in 11 patients, $3.4 \%$ of the sample, with $57 \%$ with Breslow $>4 \mathrm{~mm}$.

The time between the diagnosis of the disease and the treatment impacts on the prognosis. In our service, this time was on average, of 104 days, what can be explained by the fact that in the 
first years of the study, the flowchart and priority were still being implemented.

The patients analyzed in this study continue follow -up in our institution and will be evaluated regarding the oncologic outcome of the treatment performed.

\section{CONCLUSION}

Early stage melanoma diagnosis and treatment provide a lower morbidity, higher survival, since disease control with other non-surgical therapies is poor. The increasing number of qualified professionals, prevention campaigns and sun protection tend to provide better early detection rates of the disease. This study showed an analysis of the population seen in our hospital, which is reference for the treatment of melanoma. $\square$

\section{REFERENCES}

1. Figueiredo E, Monteiro M, Ferreira A. Tratado de Oncologia. Rio de Janeiro: Ed Revinter; 2013

2. Inca.gov.br [Internet]. Instituto Nacional de Câncer José Alencar Gomes da Silva Coordenação de Prevenção e Vigilância. Estimativa 2016: incidência de câncer no Brasil. Rio de Janeiro: Inca; 2015. [acesso 21 nov 2017]. Disponivel em: http:// www.inca.gov.br/estimativa/2016/estimativa-2016-v11.pdf

3. Fleming ID, Cooper JS, Henson DE, Hutter RVP, Kennedy BJ, Murphy GP, et al. AJCC Cancer Staging Manual. 5th ed. Philadelphia: Lippincott-Raven; 1997.

4. Balch CM, Soong SJ, Gershenwald JE, Thompson JF, Reintgen DS, Cascinelli N, et al. Prognostic factors analysis of 17,600 melanoma patients: validation of the American Joint Committee on Cancer melanoma staging system. J Clin Oncol. 2001;19:3622-34

5. Balch CM, Soong S, Ross MI, Urist MM, Karakousis CP, Temple WJ, et al. Longterm results of a multi-institutional randomized trial comparing prognostic factors and surgical results for intermediate thickness melanomas (1.0 to $4.0 \mathrm{~mm}$ ). Intergroup Melanoma Surgical Trial. Ann Surg Oncol. 2000;7:87-97.

6. Balch CM, Urist MM, Karakousis CP, Smith TJ, Temple WJ, Drzewiecki K, et al. Efficacy of $2 \mathrm{~cm}$ Surgical Margin for Intermediate Thickness Melanomas (1 to 4mm). Ann Surg. 1993;218:262-7.

7. Oxemberg J, Kane III JM. The role of radiotherapy in melanoma. Surg Clin N Am. 2014:94:1031-47.

8. Coit DG, Thompson JA, Andtbacka R, Anker CJ, Bichakjian CK, Carson, 3rd WE, et al. "Melanoma", NCCN Clinical Practice Guidelines in Oncology (NCCN Guidelines) Version 4.2014. J Natl Compr Canc Netw. 2014:12:621-9.

9. Houghton A, Coit DG, Bloomer W, Buzaid A, Chu D, Eisenberg B, et al. NCCN Melanoma practice guidelines. Oncology. 1998;12:153-77.

10. Lima Sánchez J, Sánchez Medina M, García Duque 0, Fiúza Pérez M, Carreteri, Hernández G, Fernández Palácios J. Sentinel lymph node biopsy for cutaneous melanoma: a 6 years study. Indian J Plast Surg. 2013;46: 92-97.
11. Aneja S, Brimhall AK, Kast DR, Aneja S, Carlson D, Cooper KD, et al. Improvement in patient performance of skin self-examinations after intervention With interactive education and telecommunication reminders: a randomized controlled Study. Arch Dermatol. 2012;148:1266-72.

12. Purim KSM, Sandri CO, Pinto NT, Sousa RHS, Maluf EPC. Perfil de casos de melanoma em um hospital universitário, 2003 a 2007. Rev Canc Bras. 2013;59:193-9.

13. Lebsa-Weber A, Nunes DH, Souza Filho JJ, Carvalho-Pinto C. Assessment of 496 pathological reports of melanoma diagnosed in the city of Florianopolis, SC, Brazil. An Bras Dermatol. 2007:82:227-32.

14. Moreira J, Moreira E, Azevedo F, Mota A. Cutaneous Malignant Melanoma: a Retrospective Study of Seven Years (2006 - 2012). Acta Med Port. 2014:27:480-8.

15. Naser N. Cutaneous melanoma - A 30-year-retrospective epidemiological study conducted in a city in southern Brazil, from 1980-2009. An Bras Dermatol. 2011;86:932-41.

16. Ferrari Júnior NM, Muller H, Ribeiro M, Maia M, Saches Junior JA. Cutaneous melanoma: descriptive epidemiological study. Sao Paulo Med J. 2008:126:41-7.

17. Gon AS, Minelli L, Guembarovski AL. Primary cutaneous melanoma in Londrina. An Bras Dermatol. 2001;76:413-26.

18. Vilanova CM, Lages RB, Ribeiro SM, Almeida IP, Santos LG, Vieira SC. Epidemiological and histopathological profile of cutaneous melanoma at a center in northeastern Brazil from 2000 to 2010. An Bras Dermatol. 2013;88:545-53.

19. Battisti R, Nunes DH, Lebsa-Weber A, Schweitzer LC, Sgrott I. Evaluation of the epidemiological profile and the mortality rate of the patients with primary cutaneous melanoma in Florianopolis - SC, Brazil. An Bras Dermatol 2009:84:335-42.

20. Martinez SR, Shah DR, Yang AD,Canter RJ, Maverakis E. Sentinel Lymph Node Biopsy in Patients with Thick Primary Cutaneous Melanoma: Patterns of Use and Underuse Utilizing a Population-Based Model. ISRN Dermatol. 2013:2013:1-5.

21. Morton DL, Thompson JF, Cochran AJ, Mozzillo N, Elashoff R, Essner R, et al. Sentinel-node biopsy or nodal observation in melanoma. N Engl J Med. 2006;355:1307-17.

$\begin{array}{ll}\text { Tariane Friedrich Foiato } & \text { (D) ORCID 0000-0003-0854-817X } \\ \text { Bruno Rafael Kunz Bereza } & \text { (D) ORCID 0000-0001-7738-9219 } \\ \text { Marcos Flávio Montenegro } & \text { (D) ORCID 0000-0001-6518-9332 }\end{array}$

$\begin{array}{ll}\text { Marina Riedi Guilherme } & \text { (D) ORCID 0000-0003-4765-2180 } \\ \text { Larissa Beatriz Volski } & \text { (D) ORCID 0000-0002-2740-1563 } \\ \text { Juliano Camargo Rebolho } & \text { (D) ORCID 0000-0002-9603-5309 }\end{array}$

How to cite this article: Foiato TF, Bereza BRK, Montenegro MF, Guilherme MR, Volski LB, Rebolho JC. Analysis of patients diagnosed with primary cutaneous melanoma in the last six years in the Hospital Erasto Gaertner: epidemiologic profile. An Bras Dermatol. 2018;93(3):332-6. 